führungen in die Regierungsforschung. Die Vielfalt der kurzen Beiträge, ihre Systematisierung und die Thematisierung der neuen Herausforderungen des Regierens machen die Stärken des Handbuches aus und bestätigen letztlich die Herausgeber in der gewählten Vorgehensweise.

Martin Koschkar

\title{
Deutsche Bundespräsidenten - Streifzug von Köhler bis Heuss mit zu wenig Tiefgang
}

van Ooyen, Robert Chr. und Martin H. W. Möllers (Hrsg.): Der Bundespräsident im politischen System, VS Verlag für Sozialwissenschaften, Wiesbaden 2012, 317 Seiten, € 39,95.

Diese Präsidentschaft war ohne Beispiel: Am 17. Februar 2012 trat Christian Wulff, Bundespräsident der Bundesrepublik Deutschland, nach 598 Tagen im Amt zurück. Die Umstände seines Rücktritts lähmten die Politik und lagen über dem Land wie zäher Nebel. Der Rücktritt hat eine Debatte über die Funktion und die Stellung des Bundespräsidenten in der konstitutionellen Mechanik politischer Machtausübung ausgelöst. Der von Robert Chr. van Ooyen und Martin H. W. Möllers herausgegebene Sammelband ist vor dem Rücktritt Christian Wulffs entstanden. Viele Fragen drängen sich bei der Lektüre auf, die sämtlich im Gefolge des krisenhaften Endes der Ära Wulffentstanden sind.

Der Bundespräsident gehört zu den enigmatischen Institutionen des Grundgesetzes. Zwar gibt die Verfassung in würdevoller Schlichtheit Auskunft über die Kompetenzen des Bundespräsidenten. Doch im Unterschied zu anderen Verfassungsorganen, die als Kollegialorgan konstituiert sind, lebt das Staatsoberhaupt von der Stärke der Person, mithin vom individuellen Charakter des jeweiligen Amtsinhabers. Die Attribute, teils symbolisch stark konnotiert, teils normativ überhöht, die dem Bundespräsidenten zugeschrieben worden sind, sind heute Legion: Hüter der Verfassung, Reservemacht, Verfassungsorgan unter Verfassungsorganen, pouvoir neutre. Wahrgenommen wird der Bundespräsident als Spender kollektiver Morgengaben: von Sinnstiftung über Orientierung und geistiger Führung bis hin zu moralischer Mahnung. Mit anderen Worten: „Er soll Hefe in die gesellschaftlichen Debatten rühren und zugleich den Kitt liefern, der die Gesellschaft zusammenhält." 1

Das vorliegende Buch beleuchtet die gesamte Facettenvielfalt, die das Amt des Bundespräsidenten bereithält. Unklar bleibt jedoch, unter welcher konkreten Leitfrage die insgesamt zwanzig Beiträge stehen. Die Herausgeber möchten Amt und Funktion lediglich „unter Berücksichtigung historischer Kontinuitätslinien, staatsrechtlicher und auch vergleichender Bezüge erneut auf den Prüfstand (...) stellen“ (S. 9 f.). Dies wirkt, prima facie, wie die Ankündigung eines Streifzuges durch die Villa Hammerschmidt und Schloss Bellevue. Die Lektüre der einzelnen Kapitel bestätigt diesen Eindruck.

Der Band ist in drei große Abschnitte eingeteilt. Nach Beiträgen zum Reichspräsidenten der Weimarer Republik und der Kreation des Bundespräsidenten im Parlamentarischen Rat thematisiert der zweite Abschnitt die Funktion des Bundespräsidenten. Der dritte Teil setzt sich aus Einzelportraits aller Amtsinhaber von Theodor Heuss bis Horst Köhler zusammen.

1 Berthold Kohler, Seelsorger der Nation, in: FAZ vom 19. März 2012, S. 1. 
Durch die Entwicklung einer Dreifach-Typologie zeigt Torsten Oppelland, unter welchem politischen Stern die Wahl eines Bundespräsidenten stehen kann. Die koalitionspolitische Wahl dient dazu, „ein personalpolitisches Paket zu komplettieren“ (S. 64). So einigte sich Angela Merkel 2004 mit Guido Westerwelle und Horst Seehofer auf den Kandidaten Horst Köhler. Mit der Zustimmung der FDP „war die Wahl faktisch entschieden“ (S. 67). Verfügt eine amtierende Regierungskoalition über eine stabile Mehrheit, handelt es sich um eine hegemoniale Wahl. Im Mai 1999 wurde Johannes Rau zum Präsidenten gewählt; der Erfolg eines Gegenkandidaten war gänzlich unwahrscheinlich. Der Typus der konsensuellen Wahl hingegen liegt vor, „wenn größere Parteien ohne koalitionspolitische Hintergedanken auf die Aufstellung eines Gegenkandidaten verzichten“ (S. 64). In diesem Geiste wurde Richard von Weizsäcker 1989 im Amt bestätigt.

Aus Sicht der Gewaltenteilungslehre fragt Roland Lhotta, „wie die Verwerfungskompetenz des Bundespräsidenten bei der Gesetzesausfertigung gewaltenteilungstheoretisch in den deutschen Parlamentarismus und sein institutionelles Design eingepasst werden kann" (S. 133). Das in Art. 82 GG kodifizierte materielle Prüfungsrecht des Bundespräsidenten führt im Falle seiner Anwendung „zu einer sektoralen Präsidentialisierung des parlamentarischen Systems“ (S. 135). Tritt der Präsident als Mitregent auf, dann handelt es sich bei der Gesetzgebung „nicht mehr [um] eine exklusive Funktion des Parlaments“ (S. 138). Gerade diese Analyseperspektive bietet viel Potential für eine übergeordnete Leitfrage zur Rolle des Bundespräsidenten im bundesdeutschen Parlamentarismus. Die grundsätzliche Frage nach den Auswirkungen der Veto-Position des Bundespräsidenten als Rahmenthema hätte dem gesamten Buch deutlich mehr analytischen Tiefgang verliehen.

Die Portraits der bisherigen Amtsinhaber bieten kaum etwas Neues. Hier stehen die allseits bekannten Lebensläufe der Bundespräsidenten in den angestaubten Vitrinen der Zeitgeschichtsforschung. Mit „Hummer per Düsenjet“ gelingt Hans-Heinrich Jansen eine originelle Ausnahme. Unter Bezugnahme auf bislang nicht ausgewertetes Archivmaterial berichtet er über Walter Scheels Moskau-Besuch im November 1975. Jansen belegt, dass „diese wichtige, zum Teil in der Presse auch wegen ihrer gastronomischen Üppigkeiten kritisierte Reise Scheels" (S. 15) keineswegs mit einer unbotmäßigen Ausweitung der außenpolitischen Befugnisse des Bundespräsidenten verbunden gewesen ist.

Gern liest man noch einmal etwas über Roman Herzogs Schlüsselrede vom 26. April 1997 (die als so genannte „Ruck-Rede“ in Erinnerung geblieben ist), doch dass Herzog als Schüler „nebenher“ auch Italienisch, Altbabylonisch und Hebräisch gelernt hat (S. 246), gehört zu biographisch entbehrlichem Beiwerk.

Markus Hoffmann und Alexander Stock zeichnen ein sehr dichtes Bild von Johannes Rau und seiner präsidialen Wirkung. Der Text besticht nicht nur durch seine solide Hintergrundrecherche, sondern auch durch etliche Interviews, die die Autoren mit den Akteuren aus Raus Umgebung geführt haben. Gestützt auf die insgesamt 715 Reden (S. 266), die Rau als Bundespräsident gehalten hat, entsteht eine detailorientierte und sehr gründliche Würdigung des Bundespräsidenten. Trotz Raus ceterum censeo des Zusammenführens und Versöhnens wird deutlich, dass er auch ein streng politisch agierender Amtsinhaber war. Die Unterzeichnung des Zuwanderungsgesetzes im Juni 2002 verband er mit der Empfehlung, das Bundesverfassungsgericht anzurufen. Mit diesem Schritt vermochte er, „durch Konflikt zum Konsens zu gelangen“ (S. 265). Dieser Eingriff ins Räderwerk der Gesetzgebungsarbeit zeigt die VetoMacht des Bundespräsidenten. Auch hier liegt eine empirisch wertvolle Vorlage vor, die die Herausgeber für eine analytisch schärfere Gesamtperspektive hätten nutzen können. 
Gerd Langguth beschreibt Horst Köhler als den „scheuen Patrioten“ (S. 275) - eine brillant gewählte Kurzformel für den neunten Bundespräsidenten. Zu keinem Zeitpunkt strebte Köhler dieses Amt an, der Anruf der Bundeskanzlerin am 3. April 2004, man habe sich auf ihn als Kandidaten verständigt, kam völlig unerwartet. Seine Distanz zum politischen Spiel der Kräfte blieb; ein Patriot war er aus der ganzen Tiefe seines Herzens. Seine Pflichterfüllung ließ keinen Zweifel gelten, dennoch blieb er der ökonomische Experte, dem man die Tür in die politische Arena geöffnet hatte, mithin „ein Seitenhineingenommener“ (S. 281).

Abschließend spannt Hans-Peter Schwarz den weiten geschichtlichen Bogen, der die Bundespräsidenten von Theodor Heuss bis Horst Köhler umfasst. Schwarz sieht einen historisch gewachsenen Widerspruch zwischen einer pluralistisch-zerfaserten Gesellschaft und dem Verlangen nach monarchistischer Grandezza und autoritärer Staatsgeschäftsführung. Die Bilanz fällt insgesamt negativ aus. Bedeutung und Einfluss des Bundespräsidenten „sind stark rückläufig“; sein Kapital „ist weitgehend verbraucht“ (S. 306). Für die Zukunft rechnet Schwarz mit einem Bedeutungsverlust des Amtes, „da das Amtsprestige des Bundespräsidenten durch Präsentation von Außenseitern oder Außenseiterinnen und Verlegenheitskandidaturen zwangsläufig abgewertet wird“ (S. 306).

Die Ereignisse des Jahres 2012 tauchen diese Worte in ein neues Licht. Am 18. März wurde Joachim Gauck zum Bundespräsidenten gewählt. Sein Amtsantritt wirkte wie eine Frischluftzufuhr und politischer Sekundenkleber zugleich. Durch seinen Verstand und seine Lebensklugheit, mithin durch die erhabene Autorität seiner Biographie gewinnt das Amt an Bedeutung. Hier liegt viel Stoff vor den Herausgebern, der nun in das vollständige Bild des Staatsoberhauptes einzuweben ist. Eine rasche Aktualisierung des Sammelbandes - mit analytisch geschärfter Perspektive - wäre sehr wünschenswert.

Helge F. Jani

\section{Parteien in aller Vielfalt - drei empfehlenswerte Bände ohne Redundanzen}

Holtmann, Everhard: Der Parteienstaat in Deutschland. Erklärungen, Entwicklungen, Erscheinungsbilder, Bundeszentrale für politische Bildung, Bonn 2012, 302 Seiten, € 4,50.

Korte, Karl-Rudolf und Jan Treibel (Hrsg.): Wie entscheiden Parteien? Prozesse innerparteilicher Willensbildung in Deutschland (ZPol-Sonderband 2012), Nomos Verlagsgesellschaft, BadenBaden 2012, 289 Seiten, $€$ 34,-.

Niedermayer, Oskar (Hrsg.): Handbuch Parteienforschung, VS Verlag für Sozialwissenschaften, Wiesbaden 2013, 926 Seiten, € 69,99.

Es ist allgemeiner Konsens, dass Parteien ein unverzichtbares Element westlicher Demokratien sind. Mit Artikel 21 des Grundgesetzes sind sie in der Bundesrepublik Deutschland entsprechend prominent verankert. In der Abwandlung eines Gemeinplatzes kann gesagt werden, dass ohne Parteien kein Staat zu machen ist. Drei 2012 und 2013 erschienene Bände wenden sich der analytischen Ist-Stands-Beschreibung des Parteienstaats in Deutsch- 